\title{
EVALUATION OF ANTI-INFLAMMATORY, ANALGESIC, AND ANTIPYRETIC EFFECTS OF ETHANOLIC EXTRACT OF PEDALIUM MUREX LINN. FRUITS
}

\author{
Mahendra K. Patel, Divyesh R. Mandavia, Tejas K. Patel*, Manish J. Barvaliya and C. B. \\ Tripathi**
}

\author{
Department of Pharmacology, Government Medical College, Bhavnagar - 364001, Gujarat, India. \\ *Department of Pharmacology, GMERS Medical College, Gotri - 390021, Vadodara, Gujarat, India. \\ **E-mail: cbrtripathi@yahoo.co.in
}

\begin{abstract}
This study investigated the possible anti-inflammatory, analgesic, and antipyretic effects of ethanolic extract of Pedalium murex Linn. fruits in selected experimental animal models. Anti-inflammatory activity of Pedalium murex Linn., with doses of $200 \mathrm{mg} / \mathrm{kg}$ and $400 \mathrm{mg} / \mathrm{kg}$, p.o., was evaluated by Lambda-carrageenan induced paw oedema in Wistar albino rats; analgesic activity with doses of $280 \mathrm{mg} / \mathrm{kg}$ and $560 \mathrm{mg} / \mathrm{kg}$, p.o., was evaluated by hot plate method and acetic acid induced writhing method in Swiss albino mice; and antipyretic activity with doses of $110 \mathrm{mg} / \mathrm{kg}$ and $220 \mathrm{mg} / \mathrm{kg}$, p.o., was evaluated in New Zealand white rabbits by injecting gram -ve lipopolysaccharide obtained from E. coli. Results were analysed by one way ANOVA followed by Dunnet's multiple comparison test. Pedalium murex Linn. showed significant anti-inflammatory activity from $15 \mathrm{~min}$ to $180 \mathrm{~min}$ as compared to vehicle treated animals. It was comparable to diclofenac sodium at $180 \mathrm{~min}$. The extract did not prolong the reaction time on hot plate method but significantly reduced the number of writhing after acetic acid administration. Also the extract did not show any antipyretic activity on lipopolysaccharide induced pyrexia. It is therefore concluded that the ethanolic extract of Pedalium murex Linn. fruits has an anti-inflammatory and peripheral analgesic effects.
\end{abstract}

Keywords: Anti-inflammatory, Analgesic, Antipyretic, Pedalium murex Linn., Carrageenan

\section{Introduction}

Inflammation is the defence response of body, characterised by redness, swelling, heat, pain, and loss of function to eliminate or limit the spread of an injurious agent (Purnima et al., 2010). It involves a cascade of events elicited by numerous stimuli that include infectious agents, ischemia, thermal and physical injury, and antigen-antibody interaction (Purnima et al., 2010). Non-steroidal anti-inflammatory drugs (NSAIDs) are widely used in the treatment of acute and chronic inflammation, pain, and fever. They are effective but associated with reappearance of symptoms after discontinuation. Their use is associated with adverse effects like severe gastritis, peptic ulcer, nausea, vomiting, salt and water retention, worsening of renal function in renal or cardiac and cirrhotic patients, hypersensitivity, etc. (Grosser et al., 2011). Therefore, there is a need for screening and development of anti-inflammatory drugs which are devoid of these unwanted effects. Indigenous medicinal plants can be a source of newer anti-inflammatory and analgesic drugs. The traditional knowledge on the medicinal plants should be assessed under laboratory conditions using appropriate methodology if the traditional claims are evidencesupported (Santos et al., 2011). The ethno pharmacological approach provides specific targets for a possible development of new plant-derived drugs. India has a rich heritage of medicinal herbs which are used by the local population and traditional practitioners for the treatment of several conditions.

Pedalium murex Linn. belongs to the family Pedaliaceae. It is commonly known as Bada Gokhru in India and distributed in the coastal areas of south India (Nadkarni, 1982). Pedalium murex (P. murex) Linn. is used traditionally for various ailments in India and has been investigated for its antiulcerogenic, nephroprotective, hypolipidemic, aphrodisiac, antioxidant, antimicrobial and insecticidal properties (Patel et al., 2011a,b). Phytochemical analysis of alcoholic extract of $P$. murex Linn. had shown the presence of glycosides, proteins, plant sterols, steroids, and flavanoids (Thamizh Mozhi et al., 2011). The alcoholic and aqueous extracts of P. murex Linn. have shown strong antioxidant activity (Patel et al., 2011a; Thakkar et al., 2011). Plants with antioxidant activity have shown the anti-inflammatory and analgesic effects (De las Heras et al., 1998; Cuzzocrea et al., 2001; Schinella et al., 2002; Gülçin et al., 2004; Dar et al., 2005; Sheeja et al., 2006; Niazi et al., 2009). The aqueous extract of the whole plant has been found to possess analgesic and anti-inflammatory properties (Muralidharan and Balamurugan, 2008). However, there have been no other published reports on the anti-inflammatory, analgesic, and antipyretic activities of ethanolic extract of $P$. murex Linn. fruits. The present study was aimed at evaluating the possible anti-inflammatory, analgesic, and antipyretic effects of ethanolic extract of $P$. murex Linn. fruits.

\section{Materials and methods Experimental animals}

Wistar albino rats (150-250 gm), Swiss albino mice (20-40 gm), and New Zealand white rabbits (1.5-2 kg) were used for anti-inflammatory, analgesic, and antipyretic activity, respectively. They were kept in standard laboratory condition with 12-12 hr light/dark cycle. The experimental animals were given standard laboratory diet and water ad libitum. Food was withdrawn $12 \mathrm{hr}$ before and during the experiments. The study protocol was approved by the Institutional Animal Ethics 
Committee [Animal house registration no. 577/GO/c/02/CPCSEA dated: 17/11/2011 (Housing, Breeding, and Experiments)], Government Medical College, Bhavnagar, constituted in accordance with the guidelines of Committee for the Purpose of Control and Supervision of Experiment on Animals (CPCSEA), India.

\section{Drugs and chemicals}

Ethanolic extract of P. murex Linn. fruits (Tulsi Amrit Private Ltd., Indore, India); Diclofenac sodium (Astron Research Ltd., Ahmedabad, India); Lambda-carrageenan (Sigma-Aldrich, St. Louis, MO, USA); Lipopolysaccharide (SigmaAldrich, St. Louis, MO, USA); Morphine sulphate (Troikaa Pharmaceuticals Ltd., Ahmedabad, India); and Acetic Acid (Alfa Aesar, Ward Hill, MA, USA) were used. Diclofenac sodium and Pedalium murex Linn. were dissolved in distilled water. Doses of diclofenac sodium and P. murex Linn. were selected from published reports repectively in Kulkarni et al., (2008) and Balasubramanian et al., (2008). According to species, dose calculation was carried out by using conversion factor (Ghosh, 2008). All the negative control group animals were treated with the same volume administered in test groups' animals.

\section{Anti-inflammatory activity}

Lambda-carrageenan induced paw oedema procedure was performed to measure the anti-inflammatory activity as described by Winter et al. (Winter et al., 1962). Groups with 6 animals in each group were used:

Group 1- Negative control (distilled water $1 \mathrm{ml} / \mathrm{kg}$, p.o.)

Group 2- Positive control (diclofenac sodium $25 \mathrm{mg} / \mathrm{kg}$, p.o.)

Group 3- P. murex (200 mg/kg, p.o.)

Group 4- P. murex (400 mg/kg, p.o.)

Control and test drugs were given orally before $30 \mathrm{~min}$ of Lambda-carrageenan administration. A freshly prepared suspension of Lambda-carrageenan $(1 \% \mathrm{w} / \mathrm{v}, 0.1 \mathrm{ml})$ was injected subcutaneously in the plantar region of right hind paw of each rat. A mark was made on both hind paws just below the tibiotarsal junction, and paw volume was measured up to that mark in each animal. The paw volume was measured at $0,15,30,60,120$, and 180 min of Lambda-carrageenan treatment with the help of manual plethysmometer. Reduction in the paw volume compared to control was taken as an index of antiinflammatory activity of test drug.

The percentage of anti-inflammatory activity was calculated using the formula:

$\%$ Anti-inflammatory activity $=\left(\mathrm{V}_{\mathrm{c}}-\mathrm{V}_{\mathrm{t}} / \mathrm{V}_{\mathrm{c}}\right) \times 100$ (Where $\mathrm{V}_{\mathrm{t}}$ represents the mean increase in paw volume in rats treated with test drug, and $\mathrm{V}_{\mathrm{c}}$ represents the mean increase in paw volume in control group).

\section{Analgesic activity Hot plate method}

Hot plate method was performed as described by Eddy and Leimbach (Eddy \& Leimbach, 1953). The pre-screened Swiss albino mice showed the reaction time of 3 to $5 \mathrm{sec}$ and were divided into 4 groups ( $\mathrm{n}=6$ in each group).

Group 1- Negative control (distilled water $10 \mathrm{ml} / \mathrm{kg}$, p.o.)

Group 2- Positive control (morphine sulphate $5 \mathrm{mg} / \mathrm{kg}$, s.c.)

Group 3- P. murex (280 mg/kg, p.o.)

Group 4- P. murex (560 mg/kg, p.o.)

The hot plate which consisted of an electrically heated surface (copper plate) was used for this procedure. The temperature was controlled for $55 \pm 1{ }^{\circ} \mathrm{C}$. The animals were placed on the hot plate and the reaction time was recorded by a stop-watch till the animal showed licking or jumping movements. The cut off time was considered as 15 sec. The reaction time was recorded at $0,20,60$, and 90 min following administration of the test drug.

Percentage of the prolongation of the reaction time was calculated using the formula:

$\%$ Prolongation of the reaction time $=\left(R_{c}-R_{t} / R_{c}\right) \times 100$ (Where $R_{t}$ represents the mean increase in reaction time in mice treated with test drug, and $\mathrm{R}_{\mathrm{c}}$ represents the mean increase in reaction time in control group).

\section{Acetic acid induced writhing method}

This activity was performed by the method of Dambisya and Lee (Dambisya and Lee, 1995). Swiss albino mice were divided into four groups ( $\mathrm{n}=6$ in each group).

Group 1- Negative control (distilled water $10 \mathrm{ml} / \mathrm{kg}$, p.o.)

Group 2- Positive control (diclofenac sodium $35 \mathrm{mg} / \mathrm{kg}$, p.o.)

Group 3- P. murex (280 mg/kg, p.o.)

Group 4- P. murex (560 mg/kg, p.o.)

Control and test drug were administered orally. $0.6 \% \mathrm{w} / \mathrm{v}$ acetic acid $(10 \mathrm{ml} / \mathrm{kg})$ was injected intraperitoneally 30 min after the drug administration. The number of writhes was counted over the 10 min duration after the acetic acid administration. A reduction in the number of writhes compared to the control animals was considered as an index of analgesic activity. Video recording of the whole procedure was done.

Percentage of inhibition of writhing was calculated using the formula: 
$\%$ Inhibition of writhing $=\left(\mathrm{W}_{\mathrm{c}}-\mathrm{W}_{\mathrm{t}} / \mathrm{W}_{\mathrm{c}}\right) \times 100\left(\right.$ Where $\mathrm{W}_{\mathrm{t}}$ represents the mean number of writhes in mice treated with test drug, and $\mathrm{W}_{\mathrm{c}}$ represents the mean number of writhes in control group).

\section{Antipyretic activity}

New Zealand white Rabbits were placed in separate cages and allowed to stabilise for $1 \mathrm{hr}$. Basal rectal temperature was recorded by telethermometre (readings taken twice and averaged). Pyrexia was induced in four groups ( $\mathrm{n}=6$ in each group) by injecting $0.2 \mu \mathrm{g} / \mathrm{kg}$ gram -ve lipopolysaccharide (LPS) obtained from $E$. coli intravenously through the marginal ear vein (Vogel \& Vogel, 2005). Rectal temperature was noted at $0.5,1$, and $1.5 \mathrm{hr}$ post pyrogen administration (PPA).

Group 1- Negative control (distilled water $0.2 \mathrm{ml} / \mathrm{kg}$, p.o.)

Group 2- Positive control (diclofenac sodium $15 \mathrm{mg} / \mathrm{kg}$, p.o.)

Group 3- P. murex (110 mg/kg, p.o.)

Group 4- P. murex (220 mg/kg, p.o.)

After each administration of control and test drug orally, rectal temperature was monitored at $0.5 \mathrm{hr}$ interval for 3.5 hours post-therapy (2.0-5.0 hr PPA). Reduction in rectal temperature after drug administration in the pyretic rabbits was taken as an index of antipyretic activity.

\section{Statistical analysis}

Results were analysed by one way ANOVA followed by Dunnet's multiple comparison test to determine the significance of the difference between the control group and experimental animals treated with test drug for antiinflammatory, analgesic, and antipyretic groups. All statistical calculations were carried out using Graph Pad Prism 5.04 (Trial version) statistical software. $p<0.05$ was considered as statistically significant.

\section{Results}

\section{Anti-inflammatory activity}

P. murex Linn. and diclofenac sodium produced significant inhibition of paw oedema as compared to vehicle control group. P. murex Linn. showed more earlier response than diclofenac sodium (15 min vs. $60 \mathrm{~min})$. Mean percentage of inhibition in P. murex Linn. treated groups with $200 \mathrm{mg} / \mathrm{kg}(65.87 \%)$ and $400 \mathrm{mg} / \mathrm{kg}(53.37 \%)$ doses were comparable to diclofenac sodium treated group $(71.63 \%)$ at $180 \mathrm{~min}$ (Figure 1 ).

\section{Analgesic activity Hot plate method}

There was no significant difference in the reaction time between different groups at $0 \mathrm{~min}$. Morphine showed the earlier response on $20 \mathrm{~min}$ observation. Maximum effect was reached at $1 \mathrm{hr}$. P. murex Linn. $280 \mathrm{mg} / \mathrm{kg}$ and $560 \mathrm{mg} / \mathrm{kg} \mathrm{did}$ not show significant effect on this model. Maximum percentage of prolongation with morphine and $P$. murex Linn. was 128.57 and 35.14 respectively (Figure 2).

\section{Acetic acid induced writhing method}

P. murex Linn. and diclofenac sodium significantly reduced the number of writhes. However, effect was higher in diclofenac sodium treated mice $(91.80 \%)$ than those treated with $P$. murex Linn. $200 \mathrm{mg} / \mathrm{kg}(72.13 \%)$ and $400 \mathrm{mg} / \mathrm{kg}$ $(62.30 \%)$ doses (Figure 3).

\section{Antipyretic activity}

Intravenous injection of lipopolysaccharide from $E$. coli increased the rectal temperature of control rabbits from baseline value of 39.75 to $40.63{ }^{\circ} \mathrm{C}\left(\Delta 0.88^{\circ} \mathrm{C}\right)$ at $1.5 \mathrm{hr}$ after administration. It reached to peak temperature of $41.17{ }^{\circ} \mathrm{C}$ at 3 $\mathrm{hr}\left(\Delta 1.42^{\circ} \mathrm{C}\right)$. Diclofenac sodium had significantly reduced the rectal temperature at 2.5 and $3 \mathrm{hrs}$. P. murex Linn. 110 $\mathrm{mg} / \mathrm{kg}$ and $220 \mathrm{mg} / \mathrm{kg}$ did not show significant antipyretic effect at any time interval (Figure 4). 
Patel et al., Afr J Tradit Complement Altern Med. (2013) 10(4):94-100

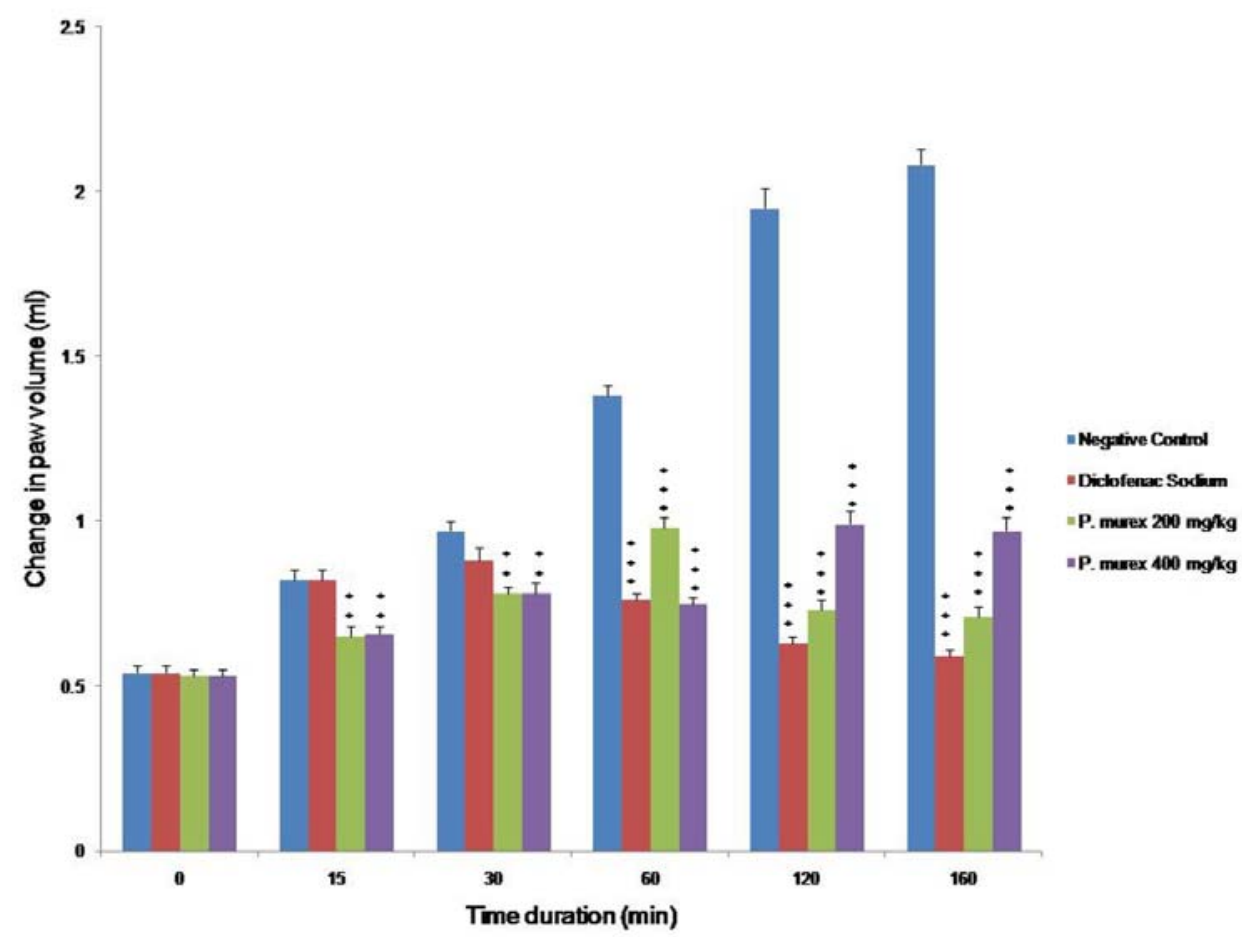

Figure 1: Anti-inflammatory activity of ethanolic extract of $P$. murex (Linn.) fruits on Lambda-carrageenan induced paw oedema in wistar albino rats $(\mathrm{n}=6)$. Values expressed as Mean \pm SEM. One way ANOVA: $* * \mathrm{P}<0.01, * * * \mathrm{P}<0.001$ by Dunnet's multiple comparison test as compared to vehicle control

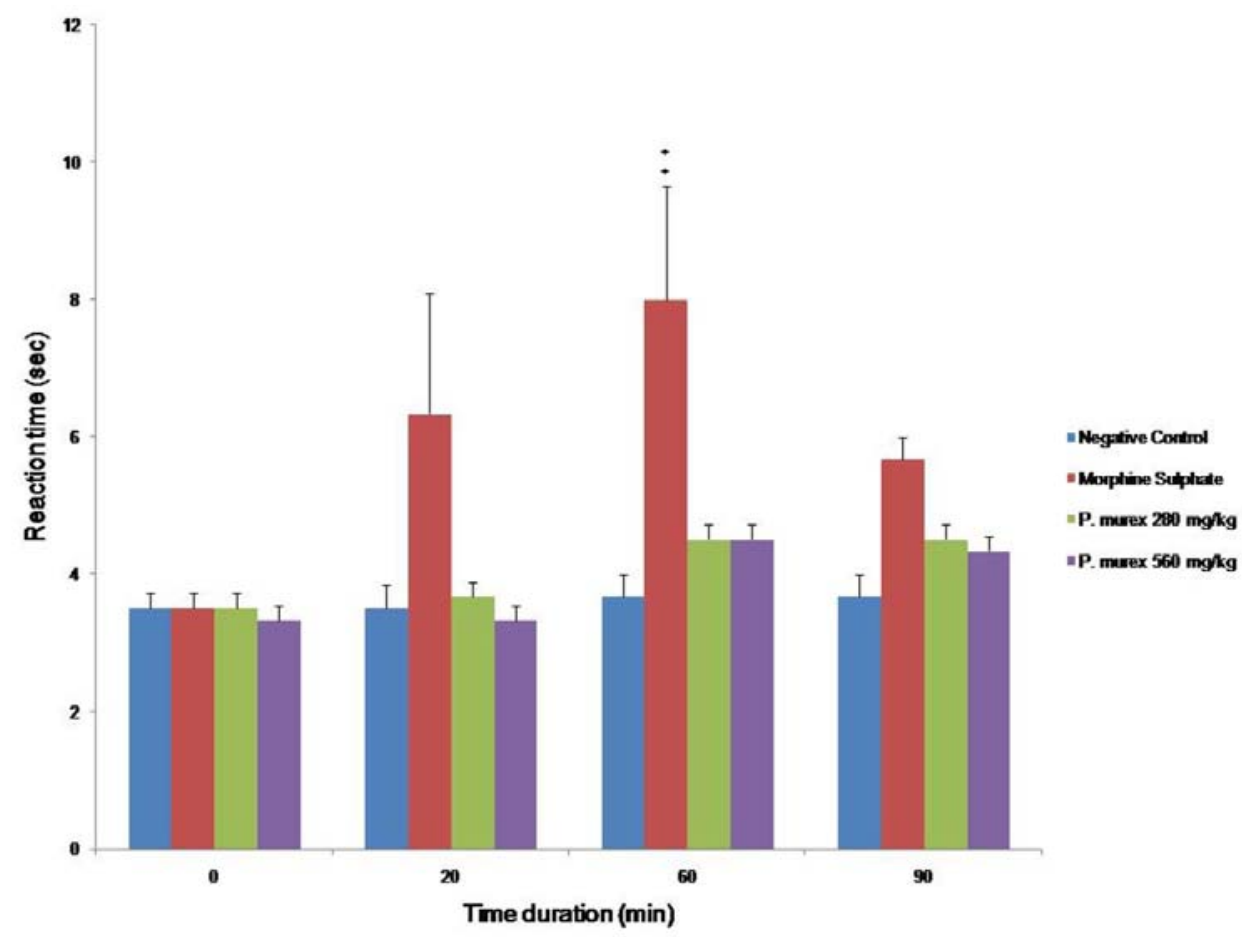

Figure 2: Central Analgesic activity of ethanolic extract of p. murex (Linn.) fruits on reaction time to hot plate method in mice $(\mathrm{n}=6)$. Values expressed as Mean \pm SEM. One way ANOVA: ${ }^{* *}<0.01$ by Dunnet's multiple comparison test as compared to vehicle control 


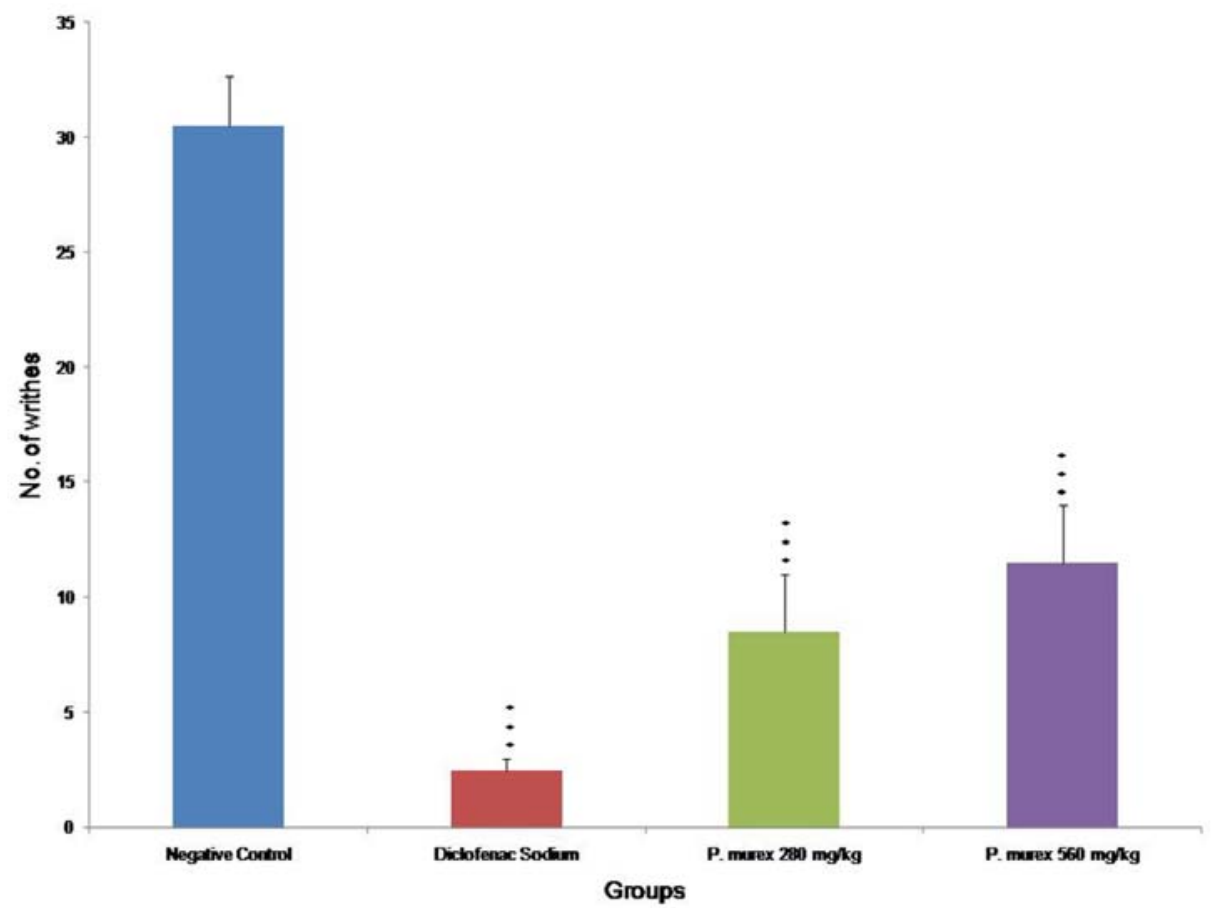

Figure 3: Peripheral analgesic activity of ethanolic extract of p. murex (Linn.) fruits in acetic acid induced writhing method in mice $(n=6)$. Values expressed as Mean \pm SEM. One way ANOVA: ${ }^{* * *} p<0.001$ by Dunnet's multiple comparison test as compared to vehicle control

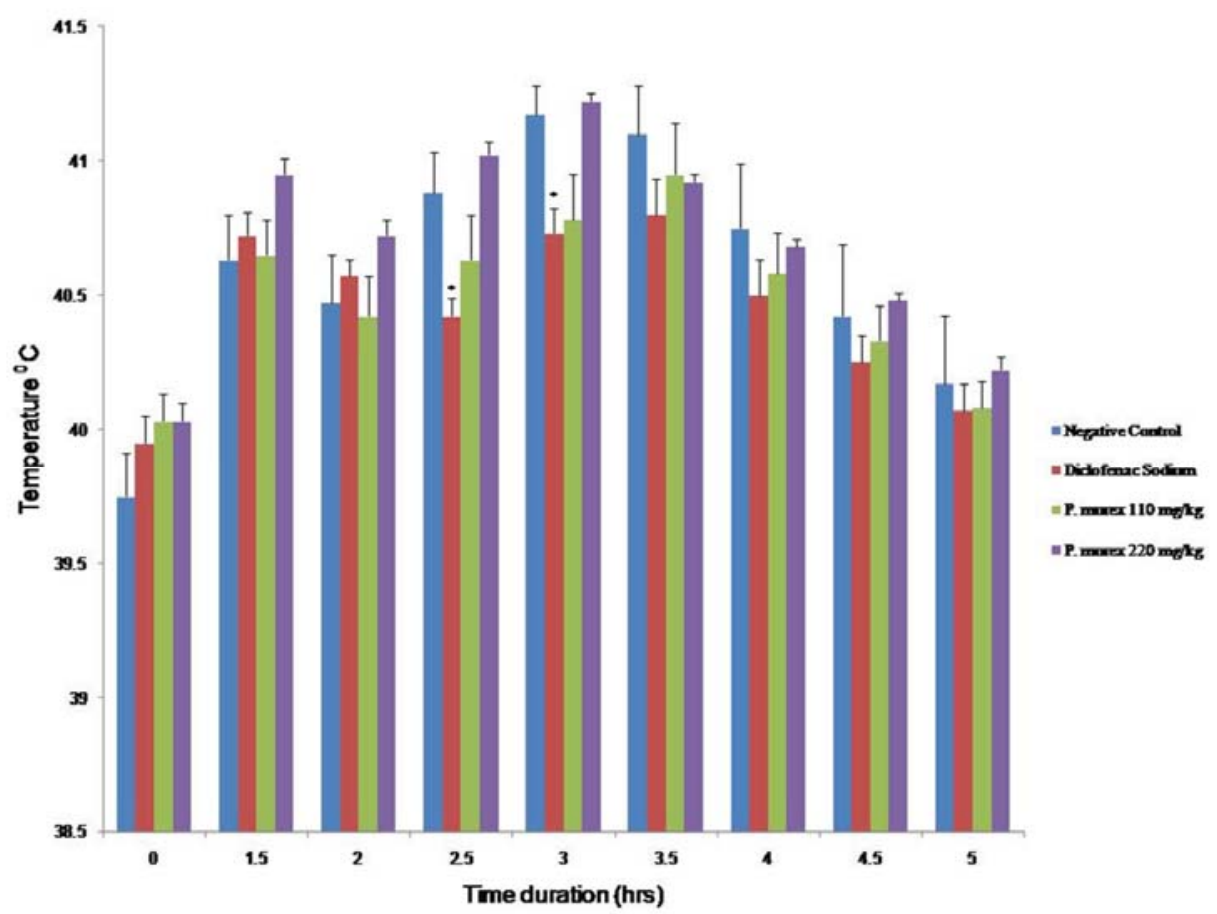

Figure 4: Antipyretic activity of ethanolic extract of p. murex (Linn.) fruits on LPS induced pyrexia in rabbits (n=6). Values expressed as Mean \pm SEM. One way ANOVA: ${ }^{*} p<0.05$ by Dunnet's multiple comparison test as compared to vehicle control

\section{Discussion}

Lambda-carrageenan induced hind paw oedema is the standard experimental model of acute inflammation. It exhibits a high degree of reproducibility. Lambda-carrageenan is not known to be antigenic and is devoid of apparent 
systemic effects. It induces a local inflammation characterised by increased vascular permeability, oedema, and neutrophil extravasations (Gamache et al., 1986). Lambda-carrageenan induced oedema is a biphasic response. The first phase is mediated through the release of histamine, serotonin, and kinins which last for $1 \mathrm{hr}$. The second phase is related to the release of prostaglandins, lysosome, bradykinins, and protease which last from the next 1 to $3 \mathrm{hrs}$ (Purnima et al., 2010). p. murex Linn. had shown the significant anti-inflammatory activity in this model. p. murex Linn. showed the earlier response at 15 min following the Lambda-carrageenan administration as compared to diclofenac sodium. It suggests that $p$. murex Linn. may have effect on the release of histamine, serotonin, and kinins. However, no dose dependent effect was seen on the early phase of inflammation by $p$. murex Linn. It had also shown the significant effect on the late phase of inflammation by Lambda-carrageenan. This is probably due to its effect on the prostaglandin related mechanisms. Mean percentage of reduction was comparable to diclofenac sodium pre-treated animals.

Inflammatory activity of Lambda-carrageenan is accompanied by the elevation in the free radicals level (Gamache et al., 1986). Nitric oxide (NO) is also the key mediator of early and late phase of inflammation (Salvemini et al., 1996). During the early phase, histamine, serotonin, and kinins release NO through activation of constitutive nitric oxide synthase (c-NOS). NO is the final common mediator of early phase of inflammation. Later on, it is released by inducible nitric oxide synthase (i-NOS) which is responsible for the late phase of inflammation. Nitric oxide synthase (NOS) and cyclo-oxygenase (COX) work together for inflammatory response. NO also leads to exaggerated production of COX (Salvemini et al., 1996). Alcoholic extract of $p$. murex Linn. fruits has shown strong nitric oxide [(200.57 \pm 4.51$) \mu \mathrm{g} / \mathrm{ml}]$, 2,2-diphenyl-1picrylhydrazyl $(\mathrm{DPPH})[(135.11 \pm 2.95) \mu \mathrm{g} / \mathrm{ml}]$, hydrogen peroxide $[(217.91 \pm 6.12) \mu \mathrm{g} / \mathrm{ml}]$, and hydroxyl radical $[(250.01 \pm$ 4.68) $\mu \mathrm{g} / \mathrm{ml}$ ] scavenging activity (Patel et al., 2011b).

Anti-inflammatory effect of p. murex Linn. could have also been due to its anti-oxidant activity. p. murex Linn. contains polyphenolics like phenolic acids and flavonoids resides (Patel et al., 2011a). Flavanoids and dietary phenolics inhibit mammalian 5-lipoxygenage and cyclo-oxygenase enzymes (Laughton et al., 1991). Nitric oxide molecules are directly scavenged by flavonoids. This process plays a role in the therapeutic effects of flavonoids (Nijveldt et al., 2001). Flavanoids also reduces release of arachidonic acid, which is a starting point for a general inflammatory response. It inhibits eicosanoid biosynthesis and neutrophil degranulation (Nijveldt et al., 2001).

Analgesic activities of $p$. murex Linn. were evaluated by the hot plate method and acetic acid induced writhing methods. These methods allow the analysis of central and peripherally mediated antinociceptive responses respectively. $p$ murex Linn. did not show any significant prolongation of the reaction time in hot plate method. NSAIDs also show the comparatively less effect than opioids in this model. It has reduced the number of writhes due to administration of acetic acid and effect was comparable to diclofenac sodium. However, the effect of both doses of P. murex Linn. was similar. Higher effect on the acetic acid-induced writhing than on the hot plate method suggests that it has a more predominant peripheral than the central analgesic effect and that the extract is working through non-opioid mechanism (Purnima et al., 2010). Bradykinin, neurokinins, and prostanoids are known mediators for acetic acid-induced writhing (Ikeda et al., 2001). Brief changes in the activity of neuronal NOS induce both long-, as well as, short-term changes in nociception in acetic acidinduced writhing in mice. Doses of nitric oxide synthase inhibitors had no effect on hot plate or tail flick latencies and inhibited acetic acid-induced writhing when administered before testing (Larson et al., 2000). Peripheral analgesic effect of $p$. murex Linn. could be due to its anti-oxidant effect. Reactive oxygen species such as superoxide and hydroxyl radical play a prominent role in the stimulation, propagation, and maintenance of inflammation, as well as pain causing tissue damage. Antioxidants, either by preventing the formation of oxygen free radicals or by scavenging them, reduce the inflammation and the associated pain (Dar et al., 2005; Cuzzocrea et al., 2001). Lipopolysaccharide elevates the body temperature by increasing the pro-inflammatory cytokines which induce the production of $\mathrm{PGE}_{2}$. It binds to $\mathrm{PGE}_{2}$ receptors on thermoregulatory neurons in the hypothalamus (Nilsberth et al., 2009). There are conflicting reports of the role of nitric oxide on fever. Riedel (1997) had reported antipyretic effect of nitric oxide, while Soszynski (2001) had reported that elevation of nitric oxide formation is involved in lipopolysccharide-induced fever (Riedel, 1997; Soszynski, 2001). NSAIDs produce antipyretic action through inhibition of $\mathrm{PGE}_{2}$ in hypothalamus. The results obtained in this study suggest that the ethanolic extract of $p$. murex Linn. fruits does not have any antipyretic activity. This may be due to lack of central activity of $P$. murex Linn. fruits.

This study has several limitations. Further studies can be performed to identify the effects of ethanolic extract of $p$. murex Linn. fruits on chronic inflammation and other analgesic models, its mechanism of action, and active ingredient.

\section{Conclusion}

Ethanolic extract of $p$ murex Linn. fruits has shown from this study that it possesses anti-inflammatory and analgesic effects without any antipyretic activity.

\section{References}

1. Balasubramanian, M. N., Muralidharan, P. and Balamurugan, G. (2008). Anti hyperlipidemic activity of Pedalium murex (Linn.) fruits on high fat diet fed rats. Int J Pharmacol. 4: 310-313.

2. Cuzzocrea, S., Riley, D. P., Caputi, A. P. and Salvemini, D. (2001). Antioxidant therapy: a new pharmacological approach in shock, inflammation, and ischemia/reperfusion injury. Pharmacol Rev. 53: 135-159.

3. Dambisya, Y. M. and Lee, T. L. (1995). Effects L-NG-nitro arginine methyl ester (L-NAME), L-NG monomethyl arginine (L-NMMA) and L-arginine on the antinociceptive effects of morphine in mice. Methods Find Exp Clin Pharmacol. 17: 577-582. 
4. Dar, A., Faizi, S., Naqvi, S., Roome, T., Zikr-ur-Rehman, S., Ali, M., Firdous, S. and Moin, S. T. (2005). Analgesic and antioxidant activity of mangiferin and its derivatives: the structure activity relationship. Biol Pharm Bull. 28: 596-600.

5. De las Heras, B., Slowing, K., Benedí, J., Carretero, E., Ortega, T., Toledo, C., Bermejo, P., Iglesias, I., Abad, M. J., Gómez-Serranillos, P., Liso, P. A., Villar, A. and Chiriboga, X. (1998). Antiinflammatory and antioxidant activity of plants used in traditional medicine in Ecuador. J Ethnopharmacol. 61: 161-166.

6. Eddy, N. B. and Leimbach, D. (1953). Synthetic analgesics. II. Dithienylbutenyl- and dithienylbutylamines. J Pharmacol Exp Ther. 107: 385-393.

7. Gamache, D. A., Povlishock, J. T. and Ellis, E. F. (1986). Carrageenan-induced brain inflammation. Characterization of the model. J Neurosurg. 65: 675-685.

8. Ghosh, M. N., Ed. (2008). Toxicity studies. Fundamentals of Experimental Pharmacology. Kolkata: Hilton \& Company; p. 176-183.

9. Grosser, T., Smyth E. and FitzGerald G. A., Eds. (2011). Anti-inflammatory, Antipyretic, and Analgesic Agents; Pharmacotherapy of Gout. Goodman \& Gilman's The Pharmacological Basis of Therapeutics. New York: McGraw Hill; p. 973.

10. Gülçin, I., Küfrevioglu, O. I., Oktay, M. and Büyükokuroglu, M. E. (2004). Antioxidant, antimicrobial, antiulcer and analgesic activities of nettle (Urtica dioica L.). J Ethnopharmacol. 90(2-3): 205-215.

11. Ikeda, Y., Ueno, A., Naraba, H. and Oh-ishi, S. (2001). Involvement of vanilloid receptor VR1 and prostanoids in the acid-induced writhing responses of mice. Life Sci. 69: 2911-2919.

12. Kulkarni, R.R., Virkar, A.D. and D'mello, P. (2008). Antioxidant and Antiinflammatory Activity of Vitex negundo. Indian J Pharm Sci. 70(6): 838-840.

13. Larson, A. A., Kovacs, K. J., Cooper, J. C. and Kitto, K. F. (2000). Transient changes in the synthesis of nitric oxide result in long-term as well as short-term changes in acetic acid-induced writhing in mice. Pain. 86(1-2): 103111.

14. Laughton, M. J., Evans, P. J., Moroney, M. A., Hoult, J. R. and Halliwell, B. (1991). Inhibition of mammalian 5lipoxygenase and cyclo-oxygenase by flavonoids and phenolic dietary additives. Relationship to antioxidant activity and to iron ion-reducing ability. Biochem Pharmacol. 42: 1673-1681.

Muralidharan, P. and Balamurugan, G. (2008). Analgesic and Anti-inflammatory activities of Aqueous extract of Pedalium murex Linn. Biomedicine. 28: 84-87.

Nadkarni, K. M., Ed. (1982). Indian Materia Medica; V. 1, Bombay: Popular Prakashan Private Limited; p. 229.

Niazi, J., Singh, P., Bansal, Y. and Goel, R. K. (2009). Anti-inflammatory, analgesic and antipyretic activity of aqueous extract of fresh leaves of Coccinia indica. Inflammopharmacology. 17: 239-244.

Nijveldt, R. J., van Nood, E., van Hoorn, D. E., Boelens, P. G., van Norren, K. and van Leeuwen, P. A. (2001). Flavonoids: a review of probable mechanisms of action and potential applications. Am J Clin Nutr. 74: 418-425. Nilsberth, C., Elander, L., Hamzic, N., Norell, M., Lönn, J., Engström, L. and Blomqvist, A. (2009). The role of interleukin-6 in lipopolysaccharide-induced fever by mechanisms independent of prostaglandin E2. Endocrinology. 150: $1850-1860$

Patel, D. K., Kumar, R., Prasad, S. K. and Hemalatha, S. (2011a). Pedalium murex Linn (Pedaliaceae) fruits: a comparative antioxidant activity of its different fractions. Asian Pac J Trop BioMed. 1: 395-400.

Patel, D. K., Laloo, D., Kumar, R. and Hemalatha S. (2011b). Pedalium murex Linn.: an overview of its phytopharmacological aspects. Asian Pac J Trop Med. 4: 748-755.

Purnima, A., Koti, B. C., Thippeswamy, A. H., Jaji, M. S., Swamy, A. H., Kurhe, Y. V. and Sadiq, A. J. (2010). Antiinflammatory, Analgesic and Antipyretic Activities of Mimusops elengi Linn. Indian J Pharm Sci. 72: 480485.

Riedel, W. (1997). Antipyretic role of nitric oxide during endotoxin-induced fever in rabbits. Int J Tissue React. 19(3-4): 171-178. (1996) Nitric oxide: a key mediator in the early and late phase of Pharmacol. 118: 829-838.

Santos, E. N., Lima, J. C., Noldin, V. F., Cechinel-Filho, V., Rao, V. S., Lima, E. F., Schmeda-Hirschmann, G., Sousa, P. T. Jr and Martins, D. T. (2011). Antiinflammatory, antinociceptive, and antipyretic effects of methanol extract of Cariniana rubra stem bark in animal models. An Acad Bras Cienc. 83: 557-566. Schinella, G. R., Tournier, H. A., Prieto, J. M., Mordujovich de Buschiazzo, P. and Ríos, J. L. (2002). Antioxidant activity of anti-inflammatory plant extracts. Life Sci. 70: 1023-1033. Sheeja, K., Shihab, P. K. and Kuttan, G. (2006). Antioxidant and anti-inflammatory activities of the plant Andrographis paniculata Nees. Immunopharmacol Immunotoxicol. 28: 129-140. fever in rats. Physiol Behav. 72(1-2): 65-72. Thakkar, J. H., Solanki, A. N., Thakkar, M. H., Solanki, H. K. and Patel, N. J. (2011). In vitro antioxidant activity of aqueous fruit extract of Pedalium murex. Int J Preclinical Pharm Res. 2: 26-29. Thamizh Mozhi, M., Mulaicharam, A. R. and Murugesh, S. (2011). Phytochemical and pharmacological studies on Pedallium murex Linn. Int J Ayurveda Res Pharm. 2: 253-258. Vogel, H. G. and Vogel, W. H., Eds. (2005). Drug Discovery and Evaluation. Berlin, Heidelberg, New York: Springer Publication; p. 773.

Winter, C. A., Risley, E. A. and Nuss, G. W. (1962). Carrageenin-induced edema in hind paw of the rat as an assay for antiiflammatory drugs. Proc Soc Exp Biol Med. 111: 544-547. 